Tropical Journal of Pharmaceutical Research February 2019; 18 (2): 223-231

ISSN: $1596-5996$ (print); 1596-9827 (electronic) (C) Pharmacotherapy Group, Faculty of Pharmacy, University of Benin, Benin City, 300001 Nigeria.

\title{
Formulation, characterization and optimization of nebivolol-loaded sustained release lipospheres
}

\author{
Muhammad Hanif ${ }^{1}$, Hafeez U Khan ${ }^{1,2 \star}$, Samina Afzal ${ }^{1}$, Abdul Majeed ${ }^{1}$, Nabila \\ Iqbal $^{2}$, Khurram Afzal ${ }^{3}$, Mehwish Andleeb ${ }^{4}$, Aisha Rauf ${ }^{5}$, Athar Farooq ${ }^{1}$ \\ ${ }^{1}$ Faculty of Pharmacy, Bahauddin Zakariya University, Multan. ${ }^{2}$ Faculty of Pharmacy, University of Sargodha, Sargodha, \\ ${ }^{3}$ Department of Food Sciences, Bahauddin Zakariya University, Multan, ${ }^{4}$ Faculty of Pharmacy and Alternative Medicines, \\ Islamia University, Bahawalpur, ${ }^{5}$ Institute of Pharmaceutical Sciences, Quaid-e-Azam University, Islamabad, Pakistan
}

${ }^{\star}$ For correspondence: Email: qarani_pharmacist@yahoo.com, Tel: (92)3368658751

\begin{abstract}
Purpose: To formulate, characterize and optimize nebivolol-loaded sustained release lipospheres (LPS) using beeswax (BW) as the drug carrier.

Methods: Nebivolol-loaded LPS were formulated using solvent evaporation technique (SET) and characterized. The impact of independent variables on responses such as percentage yield (PY), entrapment efficiency (EE) and drug release after $12 \mathrm{~h}$ (DR12) was assessed using central composite design (CCD). Numerical and graphical optimization techniques were also used to evaluate outcomes of the measured responses.

Results: Twenty micron-sized (20 - $100 \mu \mathrm{m})$, smooth spherical LPs with good rheological properties were produced. The yield ranged from 33 (F10) to $81 \%$ (F6), while EE ranged from 32 (F4 and F9) to $69 \%$ (F6). The results of rheological evaluation revealed angle of repose $>240$, Hausner's ratio $>1.5$, and Carr's index ranging from 13 to $19 \%$. Fourier-transform infrared (FTIR) spectroscopy, differential scanning calorimetry (DSC) and x-ray diffraction (XRD) revealed nebivolol and BW compatibility, and the absence of possible interactions between formulation components. Duration of nebivolol release was strongly associated with BW concentration and formulation F15 showed minimum drug release (46 $\%)$. Drug release was significantly higher in formulations with similar BW concentrations and low Tween-20 ( $T$-20) concentrations ( $F 1$ and F11) than in formulations with high T-20 concentrations (F2, $p$ $<0.05)$. The zeta potential of deflocculated LPs ranged from +15 to $+35 \mathrm{mV}$. Nebivolol release (46- 85 $\%)$ at pH 6.8 was significantly affected by BW concentration and it followed zero order model. Conclusion: The results obtained in this study have shown that BW is a suitable material for producing an effective sustained release formulation. The mechanism of drug release in nebivolol- loaded LPS is diffusion accompanied by erosion.
\end{abstract}

Keywords: Lipospheres, Nebivolol, Beeswax, Formulation, Central composite design

This is an Open Access article that uses a funding model which does not charge readers or their institutions for access and distributed under the terms of the Creative Commons Attribution License (http://creativecommons.org/licenses/by/4.0) and the Budapest Open Access Initiative (http://www.budapestopenaccessinitiative.org/read), which permit unrestricted use, distribution, and reproduction in any medium, provided the original work is properly credited.

Tropical Journal of Pharmaceutical Research is indexed by Science Citation Index (SciSearch), Scopus, International Pharmaceutical Abstract, Chemical Abstracts, Embase, Index Copernicus, EBSCO, African Index Medicus, JournalSeek, Journal Citation Reports/Science Edition, Directory of Open Access Journals (DOAJ), African Journal Online, Bioline International, Open-J-Gate and Pharmacy Abstracts

\section{INTRODUCTION}

Hypertension, congestive heart failure (CHF), myocardial infarction (MI), cerebral diseases and nephropathy result in the death of millions of people globally [1]. At present, the treatment strategies for cardiovascular diseases (CVDs) only serve as mere palliatives [2]. There is increasing demand for sustained delivery 
systems that can promote heart function [3,4]. For this purpose, novel formulations such as LSs provide great advantages. Lipospheres are sustained release formulations employed in disease conditions requiring plasma drug concentration that can be sustained for a prolonged period, and they are used for convenient delivery of semi-synthetic, synthetic and biological agents [5]. They can hold both hydrophobic and hydrophilic drugs, and they are physically stable and economically viable. In addition, LSs reduce dose frequency and side effects, and enhance patient compliance [6]. They are formulated from solid lipids characterized by low melting points $\left(65^{\circ} \mathrm{C}\right)$, good biocompatibility and biodegradability, absence of toxicity and ease of production [7]. As a drug carrier, BW can sustain drug release and enhance its bioavailability $[7,8]$.

Nebivolol, a drug used as first-line treatment for hypertension, is a selective beta-blocker which induces vasodilatation via the generation of nitric oxide (NO) [4]. Although nebivolol is highly effective and more generally accepted than other antihypertensive agents, it requires frequent dosing because of its poor solubility, bioavailability (<40\%) and short plasma half-life (2 h) $[9,10]$. Therefore, BW is usually used to improve its solubility and bioavailability. The aim of this study was to formulate, characterize and optimize nebivolol-loaded sustained release LS using BW as drug carrier.

\section{EXPERIMENTAL}

\section{Materials}

Nebivolol was a product of Nabi-Qasim Pharmaceuticals (Pvt) Ltd. (Pakistan). Potassium dihydrogen phosphate $\left(\mathrm{KH}_{2} \mathrm{PO}_{4}\right)$ and Tween-20 (T-20) were purchased from Merck (Germany). Infra-red grade cellulose dialysis tube and BW were obtained from Sigma Aldrich (USA), while potassium bromide $(\mathrm{KBr})$ was a product of Fischer Scientific (UK). Equipment used included X-ray diffractometer (Bruker AXS, USA) and Zetasizer (Malvern Instruments Ltd., UK).

\section{Preparation of LS}

Nebivolol-loaded LS were prepared using SET. Nebivolol and BW were dissolved in $50 \mathrm{ml}$ chloroform and the resultant solution was added to $\mathrm{T}-20$ preheated at $75{ }^{\circ} \mathrm{C}$ and then homogenized to obtain a pre-emulsion [12]. The pre-emulsion was mixed with cold water and stirred using a magnetic stirrer. The LS formed were recrystallized at room temperature and filtered using $0.45 \mu \mathrm{m}$ filter paper, and dried using a desiccator. The procedure was performed in triplicates with the aqueous phase and nebivolol concentration kept constant.

\section{Central composite design}

The CCD was performed using Design Expert (8.0.6.1) [11]. The different LS formulations were designed with concentrations of BW and T-20, and stirring speed (SS) as independent variables, while $P Y\left(Y_{1}\right)$, EE $\left(Y_{2}\right)$ and $D_{12}\left(Y_{3}\right)$ were the dependent variables/responses. The compatibility of nebivolol and BW was evaluated using FTIR spectroscopy, DSC and XRD. The particle sizes, rheologies, morphologies and zeta potential of the formulated LS were also determined. Release profiles of the LS were evaluated using kinetic models such as zero order, first order, Higuchi and Korsmeyer Peppas. Numerical and graphical optimization techniques were used to create conditions for producing optimum intensity of the measured responses.

\section{Rheological studies}

Rheological evaluation was carried out on the formulated LS based on the method described by Reithmeier et al [13] and Carr's index, Hausner's ratio, and angle of repose were determined (Table 1).

Table 1: Rheological parameters of formulated LS

\begin{tabular}{lcc}
\hline $\begin{array}{l}\text { Flow } \\
\text { parameter }\end{array}$ & Equation & Range \\
\hline $\begin{array}{l}\text { Carr's index } \\
(\%)\end{array}$ & $\mathbb{I}=\left[\mathrm{V}_{\mathrm{b}}-\mathrm{V}_{\mathrm{I}} / \mathrm{V}_{\mathrm{t}}\right] \times 10$ & $12-19$ \\
$\begin{array}{l}\text { Hausner's } \\
\text { ratio }\end{array}$ & $\mathrm{HR}=\mathrm{pt} / \mathrm{\rho b}$ & $<1.25$ \\
$\begin{array}{l}\text { Angle of } \\
\text { repose }\left({ }^{\circ}\right)\end{array}$ & $\operatorname{Tan} \theta=\mathrm{h} / \mathrm{r}$ & $<30$ \\
\hline
\end{tabular}

\section{Determination of PY}

The final constant weight (W) of dried LS was divided by the total weight (TW) of all solid lipids used in LS formulation to obtain the yield $(Y)$ of liposheres as in Eq 1 [14].

$\mathrm{Y}=\mathrm{W} / \mathrm{TW}$

\section{Evaluation of EE}

Portions of LS were crushed and dispersed in phosphate buffer ( $\mathrm{pH}$ 7.4) for $24 \mathrm{~h}$. After dilution, absorbance was read at $282 \mathrm{~nm}$ using UV-visible spectrophotometer, and the EE was calculated as in Eq $2[10,14]$. 
$E E=A D A / T D A \times 100$

where ADA is the actual concentration of nebivolol, and TDA is the theoretical concentration of nebivolol.

\section{Evaluation of drug release in vitro}

This lasted $12 \mathrm{~h}$ and was performed using Drug Dissolution Apparatus II USP (Paddle) immersed

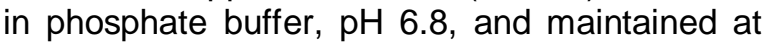
$37 \pm 0.5^{\circ} \mathrm{C}$. The LS was put in a dialysis tube containing $5 \mathrm{ml}$ of dissolution medium, and immersed in dissolution vessel containing $900 \mathrm{ml}$ of dissolution medium. After a specified time interval, an aliquot $(5 \mathrm{ml})$ was withdrawn and equal volume of freshly prepared medium was added to the vessel. After further dilution of the sample, absorbance was read at $282 \mathrm{~nm}$ [15].

\section{Drug release kinetics}

The drug release data were analyzed using kinetic models such as zero order, first order, Korsmeyer Peppas, Hixson-Crowell and Higuchi's. The mathematical equations used are shown in Eqs $3-7$.

$$
\mathrm{F}_{\mathrm{t}}=\mathrm{K}_{0} \mathrm{t}
$$

$\log F=\log F_{0}-K_{t} / 2.303$

$F=K_{H^{1 / 2}}$

$\mathrm{F}_{0}^{1 / 2}-\mathrm{F}_{\mathrm{t}}^{1 / \pi}=\mathrm{K}_{\mathrm{HC}} \times \mathrm{t}$

$\mathrm{M}_{\mathrm{t}} / \mathrm{M}_{\mathrm{s}}=\mathrm{K}_{2} \mathrm{t}^{\mathrm{n}}$

Analysis of variance (ANOVA) of two-factor interaction $(2 \mathrm{FI})$ model

$2 \mathrm{FI}$ model was analyzed using ANOVA at $5 \%$ significance level. Value of $p<0.05$ was taken as an indication that the model was significant for $Y_{1}$ and $Y_{2}$.

\section{FTIR spectroscopy}

The FTIR spectra of nebivolol, BW and nebivololloaded optimized formulation (OF) were recorded and analyzed using FTIR spectrophotometer. Before analysis, the mixture of $\mathrm{LS}$ and $\mathrm{KBr}$ was pelleted. Resolution of $2 \mathrm{~cm}^{1}$, hydraulic pressure of $150 \mathrm{~kg} / \mathrm{cm}^{2}$ and scanning range between 400 and $4000 \mathrm{~cm}^{-1}$ were used [15].

\section{Differential scanning calorimetry}

Appropriate amounts of nebivolol, BW and OF (2 mg each) were separately heated at the rate of $10{ }^{\circ} \mathrm{C} / \mathrm{min}$ from 0 to $220{ }^{\circ} \mathrm{C}$ in a sealed aluminium pan under nitrogen flow rate of $20 \mathrm{ml} / \mathrm{min}$, and analyzed using a thermal analyzer [15].

\section{X-ray diffraction}

The samples were irradiated with monochromatized X-rays of $\mathrm{Cu}-\mathrm{Ka}$ using D-8 advance X-ray diffractometer at a current of 40

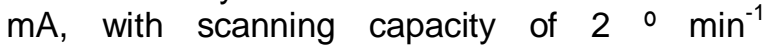

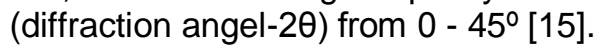

\section{Scanning electron microscopy (SEM)}

Optimized LS were positioned on a double adhesive tape on aluminum stub. Gold coating of stubs was performed under argon atmosphere, and photomicrographs of LS were obtained using scanning electron microscope (x500) at $10 \mathrm{kV}$ [15].

\section{Zeta potential and particle size measurements}

The charges on surfaces of optimized LS were measured by evaluating their electrophoretic mobilities in a U-shaped tube at $25{ }^{\circ} \mathrm{C}$ using Malvern Zetasizer [15].

\section{Statistical analysis}

Measurement data are expressed as mean \pm SD . The statistical analysis and CCD were performed using Design Expert (8.0.6.1) [16]. The optimized formulation was selected on the basis of desirability and numerical optimization functions of Design Expert. Regression analysis was also performed on the measured responses to determine the adequacy and suitability of proposed models. Where appropriate, values of $p<0.05$ were considered statistically significant.

\section{RESULTS}

\section{Formulation components and measured responses}

The PY ranged from $33(\mathrm{~F} 10)$ to $81 \%(\mathrm{~F} 6)$. Lipospheres with high BW concentrations and low T-20 concentrations formulated at low SS (F4, F9, F10, F11, F13 and F20) had PY < $50 \%$. Formulations containing the same concentrations of T-20 and BW (F4 and F10) had high PY (44 $\%)$, but the PY of F4 was significantly higher than 
that of $\mathrm{F} 10$ (33 \%) $(p<0.05)$. The EE ranged from 32 (F4 and F9) to $69 \%(F 6)$.

Although F5 and F6 had the same BW concentrations and were formulated at the same SS, both formulations had different EE (39 and $69 \%$, respectively). Formulations such as F9, $\mathrm{F} 10$ and $\mathrm{F} 11$ which had low concentrations of BW and T-20 had minimum EE (Table 2).

\section{Rheological properties}

As shown in Table 3, the rheological properties of Is showed Carr's index ranging from 13 - 19
$\%$, angle of repose $>24^{\circ}$ and Hausner's ratio $>$ 1.5 .

\section{Optimization of data and model validation}

The statistical model selected $2 \mathrm{FI}$ for PY and EE, and the suggested relations are shown in Eqs 8 and 9 for $Y_{1}$ and $Y_{2}$, respectively.

$Y_{1}=+37.23-22.55 X_{1}-7.610 X_{2}+0.014 X_{2}+$ $30.00 X_{1} X_{2}-4.33 X_{1} X_{2}-4.44 X_{2} X_{2}$

Table 2: Formulation components and measured responses

\begin{tabular}{|c|c|c|c|c|c|c|c|c|}
\hline \multicolumn{2}{|c|}{ Formulation } & \multirow{2}{*}{$\begin{array}{l}\text { Formulation } \\
\text { component } \\
\text { (Coded level) }\end{array}$} & \multicolumn{3}{|c|}{$\begin{array}{l}\text { Formulation component } \\
\text { (Actual level, \% w/v) }\end{array}$} & \multicolumn{3}{|c|}{ Response (\%) } \\
\hline & & & BW & T-20 & SS & $Y_{1}(P Y)$ & $Y_{2}$ (EE) & $Y_{3}\left(D_{12}\right)$ \\
\hline $\mathrm{F} 1$ & Facto & $-1,-1,+1)$ & 0.75 & 0.50 & 3000 & $58.00 \pm 2.71$ & $44.00 \pm 1.33$ & $72.00 \pm 3.13$ \\
\hline $\mathrm{F} 2$ & Facto & $-1,+1,+1)$ & 0.75 & 1.25 & 3000 & $67.00 \pm 2.89$ & $52.00 \pm 1.76$ & $56.00 \pm 3.36$ \\
\hline F3 & Cente & $0,0)$ & 1.25 & 0.88 & 2250 & $51.00 \pm 2.54$ & $39.00 \pm 1.82$ & $61.00 \pm 3.53$ \\
\hline $\mathrm{F} 4$ & Facto & $+1,-1,+1)$ & 1.75 & 0.50 & 3000 & $44.00 \pm 2.98$ & $33.00 \pm 2.33$ & $72.00 \pm 3.19$ \\
\hline F5 & Cente & $0,0)$ & 1.25 & 0.88 & 2250 & $50.00 \pm 2.74$ & $39.00 \pm 2.03$ & $59.00 \pm 3.87$ \\
\hline F6 & Axial & $B, 0)$ & 1.25 & 1.51 & 2250 & $81.00 \pm 2.88$ & $69.00 \pm 1.89$ & $50.00 \pm 3.45$ \\
\hline F7 & Cente & $0,0)$ & 1.25 & 0.88 & 2250 & $50.00 \pm 3.15$ & $39.00 \pm 2.24$ & $60.00 \pm 3.98$ \\
\hline F8 & Cente & $0,0)$ & 1.25 & 0.88 & 2250 & $50.00 \pm 2.97$ & $39.00 \pm 2.45$ & $60.00 \pm 4.23$ \\
\hline F9 & Axial & $3,0)$ & 1.25 & 0.24 & 2250 & $40.00 \pm 2.47$ & $33.00 \pm 2.86$ & $85.00 \pm 3.67$ \\
\hline F10 & Facto & $+1,-1,-1)$ & 1.75 & 0.50 & 1500 & $33.00 \pm 2.82$ & $31.00 \pm 1.91$ & $76.00 \pm 2.73$ \\
\hline F11 & Facto & $-1,-1,-1)$ & 0.75 & 0.50 & 1500 & $42.00 \pm 2.56$ & $33.00 \pm 2.34$ & $80.00 \pm 2.51$ \\
\hline F12 & Facto & $-1,+1,-1)$ & 0.75 & 1.25 & 1500 & $50.00 \pm 3.11$ & $42.00 \pm 1.95$ & $70.00 \pm 3.71$ \\
\hline F13 & Axial & $0,0)$ & 2.09 & 0.88 & 2250 & $44.00 \pm 3.31$ & $35.00 \pm 2.37$ & $49.00 \pm 4.23$ \\
\hline F14 & Axial & $0,0)$ & 0.41 & 0.88 & 2250 & $68.00 \pm 2.31$ & $55.00 \pm 2.18$ & $52.00 \pm 3.22$ \\
\hline F15 & Facto & $+1,+1,+1)$ & 1.75 & 1.25 & 3000 & $74.00 \pm 2.67$ & $61.00 \pm 2.07$ & $46.00 \pm 3.11$ \\
\hline F16 & Axial & $+\beta)$ & 1.25 & 0.88 & 3511 & $64.00 \pm 2.78$ & $55.00 \pm 2.24$ & $55.00 \pm 3.77$ \\
\hline $\mathrm{F} 17$ & Facto & $+1,+1,-1)$ & 1.75 & 1.25 & 1500 & $65.00 \pm 2.42$ & $54.00 \pm 1.66$ & $56.00 \pm 3.34$ \\
\hline F18 & Cente & $0,0)$ & 1.25 & 0.88 & 2250 & $50.00 \pm 3.81$ & $39.00 \pm 1.51$ & $60.00 \pm 4.03$ \\
\hline F19 & Cente & $0,0)$ & 1.25 & 0.88 & 2250 & $50.00 \pm 3.63$ & $39.00 \pm 2.23$ & $60.00 \pm 3.44$ \\
\hline F20 & Axial & $,-ß)$ & 1.25 & 0.88 & 988.6 & $45.00 \pm 2.57$ & $37.00 \pm 2.43$ & $76.00 \pm 3.78$ \\
\hline
\end{tabular}

Table 3: Rheological properties of LS

\begin{tabular}{lccc}
\hline Formulation & Angle of repose $\left(^{\circ}\right)$ & Hausner's ratio & Carr's index (\%) \\
\hline F1 & $18.00 \pm 1.25$ & $1.10 \pm 1.88$ & $16.00 \pm 1.37$ \\
F2 & $16.00 \pm 1.66$ & $1.02 \pm 1.66$ & $13.00 \pm 1.86$ \\
F3 & $20.00 \pm 1.82$ & $1.13 \pm 0.89$ & $18.00 \pm 0.77$ \\
F4 & $19.00 \pm 0.96$ & $1.11 \pm 1.77$ & $16.00 \pm 0.97$ \\
F5 & $19.00 \pm 1.23$ & $1.14 \pm 0.98$ & $19.00 \pm 1.09$ \\
F6 & $17.00 \pm 1.89$ & $1.03 \pm 0.96$ & $14.00 \pm 1.67$ \\
F7 & $18.00 \pm 1.24$ & $1.10 \pm 1.65$ & $15.00 \pm 0.96$ \\
F8 & $20.00 \pm 2.26$ & $1.12 \pm 1.83$ & $17.00 \pm 0.94$ \\
F9 & $16.00 \pm 1.09$ & $1.03 \pm 0.89$ & $13.00 \pm 1.76$ \\
F10 & $23.00 \pm 1.04$ & $1.20 \pm 1.61$ & $19.00 \pm 1.70$ \\
F11 & $20.00 \pm 1.98$ & $1.21 \pm 1.67$ & $17.00 \pm 1.83$ \\
F12 & $16.00 \pm 0.95$ & $1.01 \pm 2.33$ & $13.00 \pm 1.86$ \\
F13 & $20.00 \pm 1.79$ & $1.12 \pm 2.66$ & $18.00 \pm 1.75$ \\
F14 & $16.00 \pm 1.56$ & $1.09 \pm 1.92$ & $14.00 \pm 0.91$ \\
F15 & $17.00 \pm 1.85$ & $1.08 \pm 1.93$ & $15.00 \pm 0.88$ \\
F16 & $22.00 \pm 1.78$ & $1.11 \pm 2.07$ & $19.00 \pm 0.93$ \\
F17 & $20.00 \pm 1.46$ & $1.12 \pm 2.03$ & $18.00 \pm 1.88$ \\
F18 & $18.00 \pm 1.95$ & $1.10 \pm 1.35$ & $15.00 \pm 0.92$ \\
F19 & $16.00 \pm 1.34$ & $1.07 \pm 1.77$ & $13.00 \pm 1.72$ \\
F20 & $20.00 \pm 1.89$ & $1.12 \pm 0.97$ & $18.00 \pm 1.37$ \\
\hline
\end{tabular}


$\mathrm{Y}_{2}=+9.808+10.75 \mathrm{X}_{1}-26.39 \mathrm{X}_{2}+1.73 \mathrm{X}_{2}+$ $26.00 X_{1} X_{2}-0.013 X_{1} X_{2}-5.77 X_{2} X_{2}$

Drug release $\left(Y_{3}\right)$ followed the quadratic model and suggested Eq 10 for $Y_{3}$.

$Y_{3}=+118.08-24.347 X_{1}-42.62 X_{2}+0.02 X_{3}-$ $13.75 X_{1} X_{2}+2.65 X_{1} X_{3}-5.30 X_{2} X_{3}-9.41 X \frac{2}{1}+$ $26.07 X \frac{2}{2}+5.27 X \frac{2}{3}$

The maximum to minimum ratio for measured responses $\left(Y_{1}=2.45, Y_{2}=2.07\right.$ and $\left.Y_{3}=1.85\right)$ was $<3$.

\section{Regression analysis for the measured responses}

Predicted $\mathrm{R}^{2}$ for the measured responses were very close to their adjusted $R^{2}$, and signal to noise ratio measured from adequate precision was $>4$ (Table 4).

Table 4: Outcomes of regression analysis for the measured responses

\begin{tabular}{lccc}
\hline Parameter & $\mathbf{Y}_{\mathbf{1}}$ & $\mathbf{Y}_{\mathbf{2}}$ & $\mathbf{Y}_{\mathbf{3}}$ \\
\hline R-Squared & 0.8756 & 0.8488 & 0.9509 \\
$\begin{array}{l}\text { Adjusted R- } \\
\text { Squared }\end{array}$ & 0.8182 & 0.7790 & 0.9067 \\
$\begin{array}{l}\text { Predicted R- } \\
\text { Squared }\end{array}$ & 0.6285 & 0.8715 & 0.7899 \\
$\begin{array}{l}\text { Adequate } \\
\text { precision }\end{array}$ & 13.637 & 11.534 & 17.803 \\
Mean & $53.85 \pm 5.26$ & $57.25 \pm 5.74$ & $62.75 \pm 3.37$ \\
CV $(\%)$ & 9.77 & 10.04 & 5.37 \\
PRESS & 1073.81 & 1721.35 & 847.04 \\
\hline
\end{tabular}

\section{Three-dimensional (3D) surface graphs}

The 3D graphs showing interaction effect of two factors, while keeping the third factor constant are shown in Figure 1.

\section{In vitro drug release profiles of the formulations}

Nebivolol release time was strongly associated with BW concentration and F15 showed minimum drug release (46\%). Drug release was significantly higher in formulations with similar BW concentration and low T-20 concentration ( $F 1$ and $F 11$ ) than in formulations with high T-20 concentration (F2) $(p<0.05$; Figure 2).

\section{Outcomes of ANOVA of the measured responses}

The results of ANOVA showed that the applied models were significant $(p<0.0001)$, and values

of $f$ for $Y_{1}, Y_{2}$ and $Y_{3}$ were 15.25, 12.16 and 21.25 , respectively. The results also showed prob $>f$ (Table 5).
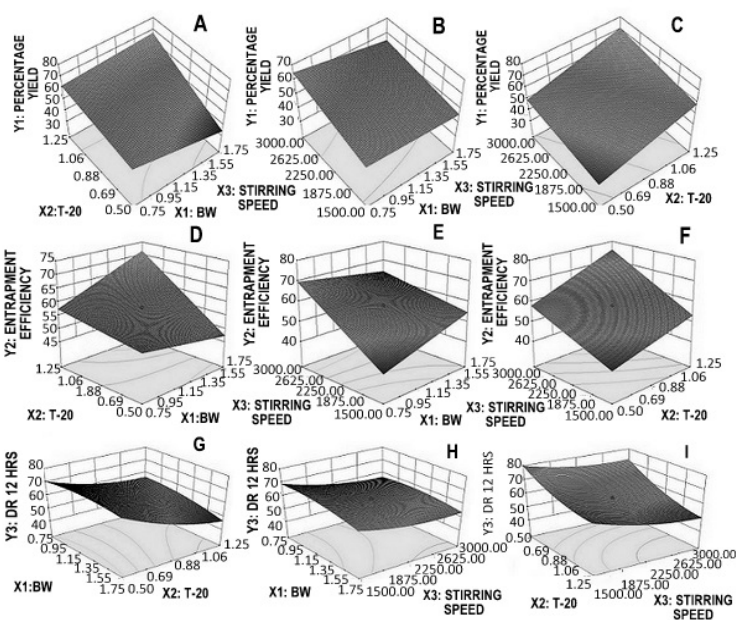

Figure 1: Three-dimensional (3D) response surface plots. A: effect of $X_{1}$ and $X_{2}$ on $Y_{1}$; $B$ : effect of $X_{1}$ and $X_{3}$ on $Y_{1}$; : effect of $X_{2}$ and $X_{3}$ on $Y_{1}$; D: effect of $X_{1}$ and $X_{2}$ on $Y_{2}$; $E$ : effect of $X_{1}$ and $X_{3}$ on $Y_{2}$; F: effect of $X_{2}$ and $X_{3}$ on $Y_{2} ; G$ : effect of $X_{1}$ and $X_{2}$ on $Y_{3} ; \mathbf{H}$ : effect of $X_{1}$ and $X_{3}$ on $Y_{3}$; I: effect of $X_{2}$ and $X_{3}$ on $Y_{3}$

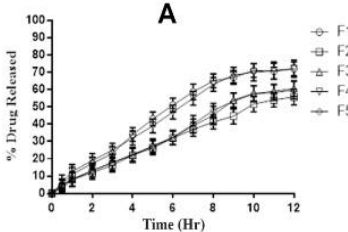

C
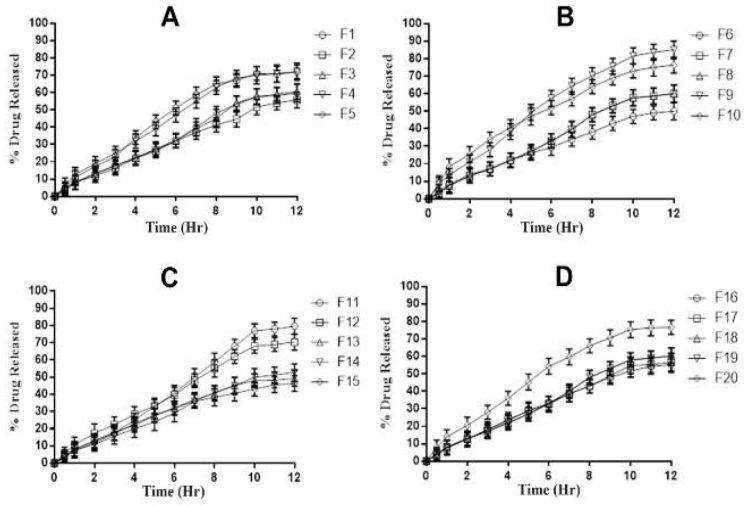

D

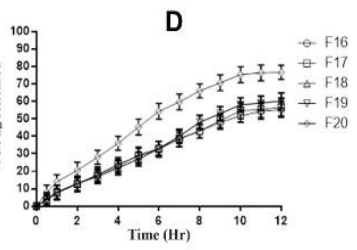

Figure 2: In vitro drug release profiles of $A$ (F1 - F5), $B$ (F6 - F10), C (F11 - F15) and D (F16 - F20)

\section{Optimized formulations}

The OF suggested by optimization techniques was prepared and characterized. The desirability of measured responses was close to 1, and prediction error was at lower level (Table 6). The drug release profiles dominantly followed zero order model since obtained $R^{2}$ for zero order was greater when compared with $R^{2}$ for the other models (Table 7).

\section{FTIR spectra and thermal characteristics}

The spectra of nebivolol and BW were compared with FTIR-spectrum of OF. Characteristic aliphatic $\mathrm{N}-\mathrm{H}$, alkanes $\mathrm{C}=\mathrm{C}$ and $\mathrm{C}-\mathrm{H}$ stretches were observed at $3185 \mathrm{~cm}^{-1}, 2319 \mathrm{~cm}^{-}$ 
1 and $1490 \mathrm{~cm}^{-1}$, respectively in nebivolol spectrum and nebivolol-loaded OF. Carbonyl and sulphur-oxy groups were also visible at 1536 and $1074 \mathrm{~cm}^{-1}$, respectively in the FTIR-spectrum of OF (Figure 3). The specific endothermic peaks relevant to melting point of $\mathrm{BW}$ and nebivolol were quite visible at $65{ }^{\circ} \mathrm{C}$ (Figure $3 \mathrm{~B}$ ) and at $221{ }^{\circ} \mathrm{C}$ (Figure $3 \mathrm{C}$ ), respectively. The peak associated with melting of nebivolol in OF at 221 ${ }^{\circ} \mathrm{C}$ was also revealed (Figure $3 \mathrm{~A}$ ).

\section{X-ray diffraction properties}

The $x$-ray diffractograms revealed the presence of characteristic peaks of nebivolol at $2 \theta$ of $25^{\circ}$, $30^{\circ}$ and $40^{\circ}$ without any impact on diffraction positions (Figure 4B). The LS of optimized formulations were spherical in shape (Figure 5).

Table 5: Analysis of variance showing the effect of factors on responses

\begin{tabular}{|c|c|c|c|c|c|c|}
\hline \multirow[t]{2}{*}{ Source } & \multicolumn{2}{|l|}{ PY $\left(Y_{1}\right)$} & \multicolumn{2}{|c|}{$\mathrm{EE}\left(\mathrm{Y}_{2}\right)$} & \multicolumn{2}{|c|}{$\mathrm{DR}_{12}\left(\mathrm{Y}_{3}\right)$} \\
\hline & $f$ & $\begin{array}{l}p \\
\text { prob }>f\end{array}$ & $f$ & $\begin{array}{l}p \\
\text { prob }>f\end{array}$ & $f$ & $\begin{array}{l}p \\
\text { prob }>f\end{array}$ \\
\hline Model & 15.25 & $<0.0001$ & 12.16 & $<0.0001$ & 21.25 & $<0.0001$ \\
\hline BW & 4.53 & 0.0013 & 1.87 & 0.01946 & 7.06 & 0.0021 \\
\hline T-20 & 57.95 & $<0.0001$ & 21.25 & 0.0005 & 110.38 & $<0.0001$ \\
\hline SS & 19.11 & 0.0008 & 37.70 & $<0.0001$ & 32.78 & 0.0002 \\
\hline $\mathrm{X}_{1} \mathrm{X}_{2}$ & 9.15 & 0.0098 & 5.76 & 0.0021 & 4.40 & 0.0032 \\
\hline $\mathrm{X}_{1} \mathrm{X}_{3}$ & 0.76 & 0.3980 & 5.76 & 0.0321 & 0.70 & 0.0042 \\
\hline$X_{2} X_{3}$ & 4.519 & 0.9474 & 0.64 & 0.0438 & 1.58 & 0.0066 \\
\hline$X_{1}^{2}$ & & & & & 7.03 & 0.0243 \\
\hline $\mathrm{X}_{2}{ }^{2}$ & & & & & 16.96 & 0.0021 \\
\hline$X_{3}{ }^{2}$ & & & & & 11.04 & 0.0077 \\
\hline LOF & 167.92 & 0.0006 & 79.89 & 0.0008 & 55.80 & 0.0002 \\
\hline
\end{tabular}

Table 6: Composition of OF

\begin{tabular}{lcccccc}
\hline $\begin{array}{l}\text { Independent } \\
\text { variable }\end{array}$ & $\begin{array}{c}\text { Optimum } \\
\text { level }\end{array}$ & $\begin{array}{c}\text { Dependent } \\
\text { variable/response }\end{array}$ & $\begin{array}{c}\text { Predicted } \\
\text { value }\end{array}$ & $\begin{array}{c}\text { Observed } \\
\text { value }\end{array}$ & $\begin{array}{c}\text { Prediction } \\
\text { error }\end{array}$ & $\begin{array}{c}\text { Desirability } \\
\text { level }\end{array}$ \\
\hline $\mathrm{X}_{1}$ & 1.75 & $\mathrm{Y} 1$ & 71.75 & 75.8 & 1.54 & \\
$\mathrm{X}_{2}$ & 1.25 & $\mathrm{Y} 2$ & 77.71 & 78.8 & 1.8 & 0.891 \\
$\mathrm{X}_{3}$ & 3000 & $\mathrm{Y} 3$ & 43.83 & 46.7 & 1.5 & \\
\hline
\end{tabular}

Table 7: Release kinetics of LS formulations

\begin{tabular}{|c|c|c|c|c|c|c|c|c|c|c|}
\hline \multirow[t]{2}{*}{ Formulation } & \multicolumn{2}{|c|}{ Zero order } & \multicolumn{3}{|c|}{ First order } & \multicolumn{2}{|c|}{ Higuchi } & \multirow{2}{*}{$\begin{array}{c}\text { Hixson- } \\
\text { Crowell } \\
K_{H C}\end{array}$} & \multicolumn{2}{|c|}{$\begin{array}{c}\text { Korsmeyer- } \\
\text { Peppas }\end{array}$} \\
\hline & $R^{2}$ & $K_{0}$ & $R^{2}$ & $K_{1}$ & $R^{2}$ & $K_{H}$ & $R^{2}$ & & $\boldsymbol{R}^{2}$ & $N$ \\
\hline $\mathrm{F} 1$ & 0.9949 & 7.265 & 0.8566 & 0.345 & 0.8731 & 12.716 & 0.8798 & 0.031 & 0.9617 & 0.989 \\
\hline $\mathrm{F} 2$ & 0.9897 & 6.567 & 0.8966 & 0.189 & 0.9176 & 11.188 & 0.8583 & 0.022 & 0.9578 & 1.021 \\
\hline F3 & 0.9877 & 7.355 & 0.8898 & 0.278 & 0.9027 & 17.341 & 0.8865 & 0.043 & 0.9876 & 1.022 \\
\hline $\mathrm{F} 4$ & 0.9897 & 8.345 & 0.9045 & 0.176 & 0.8635 & 15.156 & 0.8758 & 0.021 & 0.9856 & 0.981 \\
\hline F5 & 0.9912 & 9.243 & 0.9256 & 0.177 & 0.8324 & 14.765 & 0.7898 & 0.027 & 0.9798 & 0.890 \\
\hline F6 & 0.9933 & 8.765 & 0.8763 & 0.156 & 0.8817 & 16.254 & 0.8495 & 0.031 & 0.9848 & 0.904 \\
\hline F7 & 0.9907 & 8.135 & 0.9374 & 0.099 & 0.8557 & 14.546 & 0.8145 & 0.023 & 0.9598 & 0.887 \\
\hline F8 & 0.9934 & 7.354 & 0.9532 & 0.343 & 0.8917 & 18.423 & 0.8732 & 0.021 & 0.9298 & 0.917 \\
\hline F9 & 0.9812 & 7.134 & 0.8684 & 0.423 & 0.9198 & 16.675 & 0.8912 & 0.032 & 0.9842 & 0.899 \\
\hline F10 & 0.9943 & 7.287 & 0.9067 & 0.257 & 0.9234 & 18.345 & 0.8548 & 0.024 & 0.9897 & 1.012 \\
\hline $\mathrm{F} 11$ & 0.9941 & 6.287 & 0.8994 & 0.232 & 0.9334 & 17.214 & 0.8267 & 0.018 & 0.9768 & 0.932 \\
\hline F12 & 0.9777 & 7.798 & 0.8190 & 0.231 & 0.8767 & 12.657 & 0.8187 & 0.029 & 0.9165 & 0.904 \\
\hline F13 & 0.9944 & 7.564 & 0.8588 & 0.199 & 0.8987 & 11.089 & 0.8756 & 0.024 & 0.9698 & 1.065 \\
\hline F14 & 0.9767 & 8.213 & 0.8744 & 0.324 & 0.8766 & 13.467 & 0.8498 & 0.034 & 0.9786 & 0.896 \\
\hline F15 & 0.9987 & 8.378 & 0.9143 & 0.213 & 0.9033 & 17.367 & 0.8576 & 0.025 & 0.9897 & 0.916 \\
\hline F16 & 0.9879 & 7.678 & 0.8878 & 0.254 & 0.8788 & 15.247 & 0.8687 & 0.032 & 0.9896 & 0.919 \\
\hline F17 & 0.9989 & 8.187 & 0.8033 & 0.222 & 0.8876 & 14.876 & 0.8997 & 0.037 & 0.9765 & 0.893 \\
\hline F18 & 0.9898 & 7.665 & 0.9189 & 0.167 & 0.8345 & 13.258 & 0.8898 & 0.019 & 0.9856 & 0.993 \\
\hline F19 & 0.9859 & 8.987 & 0.8978 & 0.213 & 0.8934 & 20.456 & 0.8667 & 0.034 & 0.9156 & 0.985 \\
\hline F20 & 0.9976 & 7.567 & 0.8788 & 0.213 & 0.8853 & 13.348 & 0.8745 & 0.028 & 0.9387 & 0.988 \\
\hline
\end{tabular}



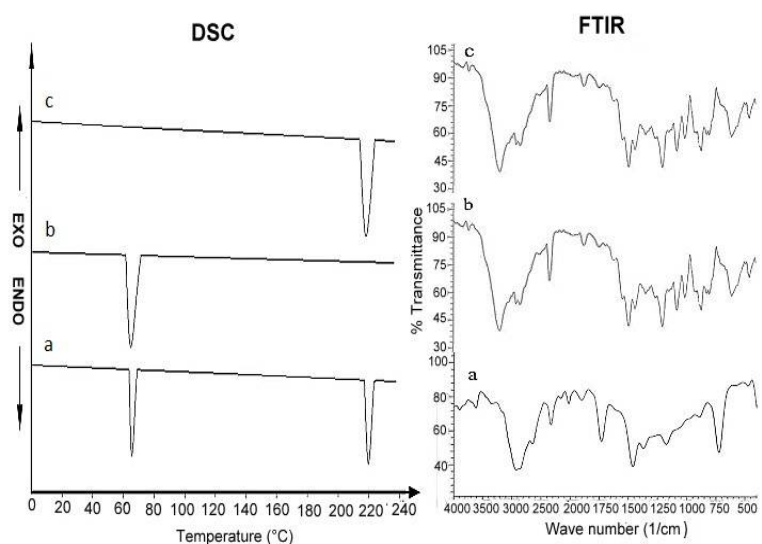

Figure 3: Thermograms and FTIR spectra. A: thermogram and FTIR spectrum of BW; $B$ : thermogram and FTIR spectrum of nebivolol; $\mathrm{C}$ : thermogram and FTIR spectrum of nebivolol-loaded optimized LS

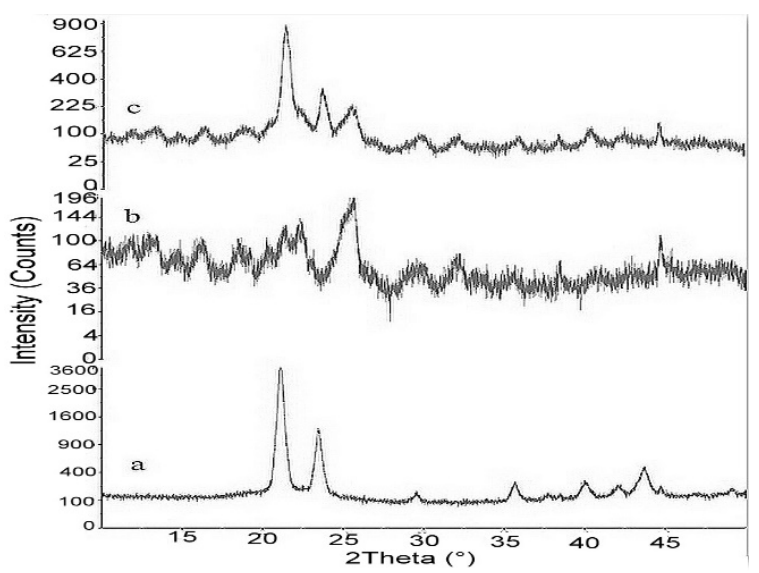

Figure 4: X-ray diffraction patterns of (a) BW, (b) nebivolol, and (c) nebivolol-loaded optimized LS

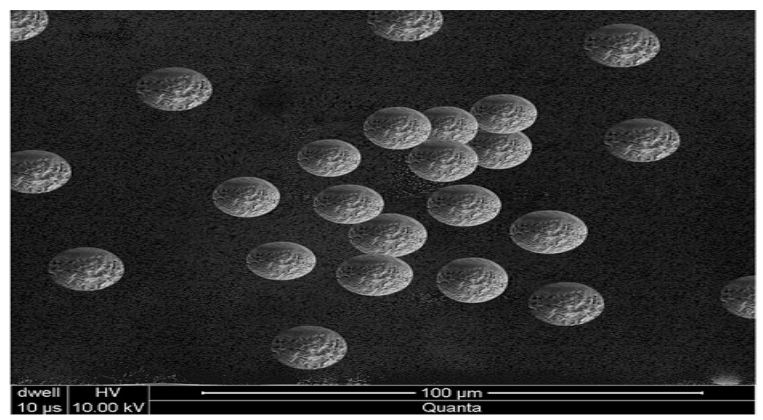

Figure 5: Scanning electron micrograph of OF

\section{Particle size and zeta potential}

The size distribution of the LS ranged from 20 to $100 \mu \mathrm{m}$ (Figures $6 \mathrm{~A}$ ), while the major fraction (55 $\%)$ of LS had a mean size of $50 \mu \mathrm{m}$. The zeta potential of OF was in the range of +15 to +35 $\mathrm{mV}$ (Figure 6B).
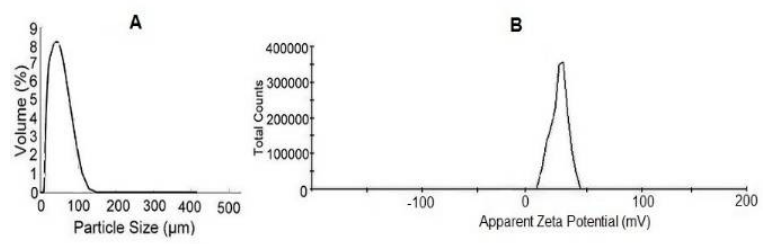

Figure 6: Particle size distribution and zeta potential curves. A: particle size distribution of OF; B: zeta potential curve of OF

\section{DISCUSSION}

Hydrophilic and lipophilic drugs can be successfully delivered into deep and peripheral tissues by encapsulating them with crystalline lipids as LS. Lipospheres offer more advantages than the single-unit systems with respect to their uniform distribution in the gastrointestinal tract resulting in uniform absorption of the encapsulated drug [5]. The present study examined the formulation and characterization of nebivolol-loaded LS using BW as drug carrier. In this study, twenty micronsized LS were produced. The results of DSC analysis and FTIR spectroscopy did not reveal absence or shift of any principal peaks of nebivolol and BW either in the spectrum of OF or individual spectra, and thermograms of nebivolol with BW. These results suggest compatibility of nebivolol and BW, and are in agreement with those previously reported [17].

The pattern of X-ray diffraction of OF revealed sharp and scattered peaks of nebivolol, an indication that nebivolol may have remained in crystalline form and that the process of formulation did not produce any negative effects on it [18]. The ratio of BW to surfactant strongly influenced rheology, morphology, PY, EE and size distribution of formulated LS. High concentrations of T-20 and SS contributed significantly to the production of free-flowing, smooth, spherical and micron-sized LSs [19].

These results are in agreement with those previously reported for lipid-based microparticles of somatostatin and oxybenzone $[8,13]$. The zeta potential of OF appears to suggest good stability since positive charge would naturally generate electrostatic repulsion between LSs, thereby preventing their aggregation [19]. It appears that increased concentrations of $\mathrm{BW}$ and T-20 are favorable conditions for producing high PY and $E E$, and that attainment of both requires concomitant increase in SS [17]. Low PY and EE may be associated with increased aggregation of lipids at low concentration of $\mathrm{T}-20$, while high concentration of T-20 may prevent drug loss in 
external phase and stabilization of lipid microparticles [17].

In this study, increased concentrations of BW, $T-20$, and $S S$ resulted in increases in $P Y$ and $E E$ (for $Y_{1}$ and $Y_{2}$ ). This suggests that BW, T-20 and SS may have positive impacts on $P Y$ and EE. For $Y_{1}$, the terms $X_{1}, X_{2}, X_{3}$, and $X_{1} X_{2}$ were significant, an indication that BW, T-20, and SS may significantly affect $P Y$ [11]. The interaction of BW with T-20 $\left(X_{1} X_{2}\right)$ and $T-20$ with $S S\left(X_{2} X_{3}\right)$ were synergistic with respect to $Y_{1}$ and $Y_{2}$ [16]. High $X_{1}$ negatively affected $Y_{3}$, an indication that an increase in BW concentration may retard drug release [18]. In addition, BW interaction with T-20 $\left(X_{1} X_{2}\right)$ produced sustained release nebivolol-loaded LS. However, the role of SS was critical. These results are in agreement with those previously reported [19].The drug release followed a zero order model. It is possible that the underlying mechanism of drug release involves diffusion accompanied by erosion $[3,19]$. The selection of OF was made on attainment of maximum $\mathrm{PY}$, maximum $\mathrm{EE}$ and minimum $\mathrm{DR}_{12}[20]$.

\section{CONCLUSION}

The results obtained in this study have shown that $\mathrm{BW}$ is a suitable material for producing a good sustained release formulation of nebivolol. The mechanism of drug release in nebivololloaded LS involves diffusion and erosion.

\section{DECLARATIONS}

\section{Acknowledgement}

The authors acknowledge with thanks NabiQasim Pharmaceuticals (Pvt) Ltd, Lahore, Pakistan for providing nebivolol, and Bahauddin Zakariya University for providing the laboratory facilities used in the study.

\section{Conflict of Interest}

No conflict of interest associated with this work.

\section{REFERENCES}

1. Whelton P, He J, Appel LJ. Primary prevention of hypertension: Clinical and Public health advisory from the National High Blood Pressure Education Program. JAMA. 2002; 288: 1882-1888.

2. Flack JM, Nasser SA. Benefits of once- daily therapies in the treatment of hypertension. Vascular Health Risk Management. 2011; 7: 777-787.

3. Dhiman MK, Yedurkar PD, Sawant KK. Buccal bioadhesive delivery system of 5-fluorouracil:
Optimization and characterization. Drug Dev. Ind. Pharm. 2008; 34: 761-770.

4. Pouton CW, Porter CJ. Formulation of lipid-based delivery systems for oral administration: materials, methods and strategies. Adv. Drug Deliv. Rev. 2008; 60: 625-637.

5. Jelvehgari $M$, Valizadeh $H$, Motlagh RJ, Montazam $H$. Formulation and physicochemical characterization of buccoadhesive microspheres containing diclofenac sodium. Adv. Pharm. Bull. 2014; 4 (3): 295-301.

6. Passerini $N$, Perissutti $B$, Albertini $B$, Voinovich $D$, Moneghini $M$, Rodriguez $L$. Controlled release of verapamil hydrochloride from waxy microparticles prepared by spray congealing. J. Control Release. 2003; 88: 263-275.

7. Mehner W, Mader K. Solid lipid nanoparticles: production, characterization and applications. Adv. Drug Deliv. Rev. 2001; 47: 165-196.

8. Goma YA, Darwish IA, Boraei NA, El-Khordagui LK. Formulation of wax oxybenzone microparticles using a factorial approach. J. Microencapsul. 2010; 27 (7): 628639.

9. Van-Bortel LM, Fici F, Mascagni F. Efficacy and tolerability of nebivolol compared with other antihypertensive drugs: a meta-analysis. Am. J. Cardiovasc. Drugs. 2008; 8 (1): 35-44.

10. Sule SS, Frishman W. Nebivolol: new therapy update. Cardiol. Rev. 2006; 14 (5): 259-264.

11. Wu X, Li G, Gao Y. Optimization of the preparation of nalmefene-loaded sustained release microspheres using central composite design. Chem. Pharm. Bull. 2006; 54 (7): 977-981.

12. Milak S, Medlicott N, Tucker IG. Solid lipid microparticles containing loratadine prepared using a micromixer. Journal of Microencapsulation. 2006; 23: 823-831.

13. Reithmeier H, Herrmann J, Gopferich A. Development and characterization of lipid microparticles as a drug carrier for somatostatin. Int. J. Pharm. 2001; 218: 133143.

14. Momoh MA, Kenechukwu FC, Attama AA. Formulation and evaluation of novel solid Lipid microparticles as a sustained release system for the delivery of metformin Hydrochloride. Drug Deliv. 2013; 20: 102-111.

15. Jaspart S, Piel G, Delattre L, Evrard B. Solid lipid microparticles: formulation, preparation, characterization, drug release and applications. Expert Opin. Drug Deliv. 2005; 2 (1): 75-87.

16. Nandy BC, Mazumder B. Formulation and characterizations of delayed release multi-particulates system of indomethacin: Optimization by response surface methodology. Curr. Drug Deliv. 2014; 10: 72-86.

17. Patil SB, Sawant KK. Development, optimization and in vitro evaluation of alginate mucoadhesive microspheres of carvedilol for nasal delivery. J. Microencapsul. 2009; 26 (5): $432-443$.

18. Narendra C, Srinath MS, Prakash-Rao B. Development of three layered buccal compact containing metoprolol 
Hanif et al

tartrate by statistical optimization technique. Int. J. Pharm. 2005; 304: 102-114.

19. Barakat $S N$, Yassin $A B$. In vitro characterization of carbamazepine-loaded precifac lipospheres. Drug Deliv. 2006; 13: 95-104.
20. Das S, Chaudhury A. Recent advances in lipid nanoparticle formulations with solid matrix for oral drug delivery. AAPS Pharm. Sci. Tech. 2011; 12: 62-76. 